\title{
The Effect of Perceptual Propinquity on Double Demotivation in Conditions of Over-and-Under-Payments
}

\author{
Leo Marai* \\ Psychology Strand, University of Papua New Guinea
}

\begin{abstract}
The inter-dynamic symbiosis between employees' motivation and social contact is crucial in our understanding of behavioral management and as such, this study investigates the effect of perceptual propinquity on double demotivation in a repeated subject design. There were two hypotheses. Firstly, it is hypothesized that the subjects who are highly and lowly paid as compared to their counterparts of same level will be demotivated (double demotivation) than those that are equitably paid. Secondly, it is predicted that the subjects who are highly and lowly paid and at a close propinquity from their counterparts of the same level (perceptual propinquity) will be more demotivated than those whose propinquity is far from their counterparts, whereas for those equitably paid, there will be no demotivation. A total of 132 undergraduate university students were instructed to imagine working in the same organization (Scenario A) and view a similar colleague working in the same organization, and for a different organization (Scenario B) in three conditions of low, high, and equitable were told that a counterpart doing the same job is paid more, less or equitable as compared to them respectively and then, they rated their job satisfaction and provide explanations for their ratings. Consistent with Social Equity Theory (SET), both underpaid and overpaid groups has significantly less motivation than the equitably paid groups. Furthermore, the results do support the hypothesis that the closer in propinquity for workers paid differently, either high or low as compared to their counterparts of the same level, thus the demotivation effect is greater than those far in propinquity for doing the same job.
\end{abstract}

Key Words: Double demotivation, perceptual propinquity.

\section{INTRODUCTION}

In our world of work, pay and motivation are crucial factors in organizational success, or, failure, and both concepts occur synergistically in the context of employeeorganizational dynamics. The principle issue of equity in pay and performance resonate on the ideology of distributive justice [1]. This management notion however, does not equate well in real work life niche. In particular, there are salary discrepancies among workers performing the same job. As a result of such pay inequity, there are detrimental effects produced on the employees' work motivation. In retrospect, various studies have confirmed such demotivating effects on the work psychology of employees [2-4]. One specific salient effect that several studies have observed is double demotivation [2-4]. As empirically defined, double demotivation is simply when a person performing the same task of the same level of qualification is paid differently as compared to (one higher and one lower) is demotivated than those who are equitably paid $[2,3,5]$. The double demotivation effect has been linked to other psychological constructs including, personality [6], intrinsic motivation [7, 8], and negative social affections [4, 9]. Although these studies have broaden our understanding of work motivation in context of salary differential, double demotivation has not been externally examined in terms of propinquity

*Address correspondence to this author at the Psychology Strand, University of Papua New Guinea; E-mail: marail@upng.ac.pg between individual subjects or workers performing the same task but paid differently in order to observe its effect. In order to investigate this proposal, it is crucial that the social and cognitive dimension of the individual be observed synergistically in the context of pay discrepancies. By combining the cognitive and ecological theoretical perspectives on de-motivation, the present study seeks to assess the effect of propinquity on double demotivation among a sample of university students.

The theoretical underpinning of double de-motivation lies in social equity theory (SET) [10], which expands from equity theory of Adams [11] to include inter-group relations. In particular, SET predicts that under-paid groups will find inter-group inequity emotionally painful, and withdraw input to match comparatively low salary outcomes, and so restore some sense of social justice. As well, amongst the higher paid group, SET predicts that attempts to restore social equity by working harder to reflect higher pay will be impractically, because nobody can work 10 times harder than their colleagues. Consequently, equity sensitive and responsive high paid workers will experience guilt, and attempt to restore their self respect and sense of social justice by convincing themselves that they somehow deserve high pay. They will develop an attitude of superiority. To the extent that such attitudes and delusions will not motivate the higher paid workers to work to their maximum capacity, they, too, will become de-motivated.

The experimental studies evolving from SET prediction on pay differences among subjects performing the same task 
have revealed the existence of double demotivation [2]. Similarly, a number of field studies conducted in work environment comparing workers paid differently and performing the same jobs have confirmed these findings [2 (Study II), 4]. Replicated studies have extended the support of double demotivation hypothesis among subjects in experiment [2, (Study I)] as well as workers in organizational settings [2 (Study II), 4]. Furthermore, double demotivation [2, 4, 6] and its effect on anxiety, depression, hopelessness [4], psychological withdrawal [9], personality variable of equity sensitivity [6] and team work [12] has been established. Hence, all these findings on double demotivation are derived from the cognitive conceptualization of the person that is encapsulated and embedded within the tenets of SET.

Although these psychological constructs form the "psychological core" of the individual and can be considered as "internal" or cognitive aspects of the person in relation to double demotivation, what remains to be explored are the "external factors" that moderate the demotivation effect on an individual during his or her perceptual analysis of the differential salary payments. This type of analysis reflects an ecological approach to social knowing. Inspired by the work of J.J. Gibson in object perception [13, 14], several theorists have suggested that much of the important activity in social understanding occurs immediately during perception [15$26]$, rather than as the result of complex inferential activity, however automated [27]. Even Fiske and Taylor [27] succinctly argued in support of the ecological approach by advancing that:

"While there is no doubt that social perceives actively construct interpretations of the world around them, it is also true that reality imposes constraint on the process. Essentially, this complaint has been raised by the Gibsonians, who argue for careful analysis of objective stimulus properties and a of possible perceiver-stimulus interactions .... Perception is not all in the head; at least some of it is out in the world." [27, p.556, emphasis added].

According to Zebrowitz [28], the ecological approach emphasizes external stimulus information and the organization inherent in it, rather than the organization constructed or imposed by the perceiver. Organization is "inherent in a stimulus" for a particular perceiver, based on that person's history of perceptual experiences. A particular stimulus offers particular behaviours to a perceiver, and the perceiver is reciprocally attuned or sensitive to particular stimulus properties. The Gibsonian approach is called "ecological perception" because it emphasizes perceivers interacting with their environment and embedded in their own characteristics niche [27].

Although the Gibsonian ecological approach emphasizes the analysis of perception and the stimulus interacting with the person in the environment for explaining a particular set of behavior, an integration of it with social equity theory on double demotivation with perceptual propinquity into a gestalt would enhanced our conceptualization of double demotivation in a broader context of work motivation.

One line of pursuing such argument is to consider the influence of propinquity in evaluating motivation demotiva- tion dichotomy among individuals and specifically, their perceptions of the salary levels between themselves. The importance of propinquity in regard to double de-motivation is imminent because in the analysis of pay differential between subjects including those paid equitably and performing the same task, the beholder's perception of the distance might influence the way he or she assess the pay level in comparison to others of the same level. This argument is derived from studies on propinquity in relation to perception [29-31]. Hence, perceptual propinquity may be the critical factor that account for the magnitude of double demotivation effect.

The term propinquity simply means a measure of distance between two objects (in this case the person and the distance of pay with counterpart on the same level) and how one perceives and evaluate it in reference to a variable of interest. In analyzing the display of behavior, it is quite critical to evaluate its strength on the basis of the distance between the variable assessed and behavior in question. In this case, a worker's perception of the physical distance and in particular, his or her nearness (perceptual propinquity) from a similar colleague and the motivational reaction that results from such evaluation in terms of salary payment defines propinquity.

The literature and studies on perception and distance have generally shown that the more friendly and intimate a person feels towards another, the closer he or she will stand. For example, Patterson and Sechrest [32] found that people who want to be friendly choose smaller distance while Allgeier and Byrne [33] study reveals that people who are sexually attracted to each other stand close. Even in a classical study conducted by Milgram [34,35] on obedience to authority, he found that bringing the victim ("learner") closer to the subject ("teacher") reduced obedience. This demonstrates that the subject has humanitarian concern for the victim's safety when the distance between them is reduced despite the authority's persistence for the electric shock to be increased. In a group study, Seta, Paulus, and Schkade [36] found that for a complex task, larger groups performed worse than smaller groups when given competitive instructions and between when given cooperative instructions. They also found that cooperative groups performed better when they were in close proximity and competitors performed better between when they were not in close proximity.

The common thread of finding that runs through these studies on propinquity show that the closer a person or group is to another one, the relationship would be more conducive, especially in a favorable context, however, an essential relevant question that remain unexplored in the literature and studies on propinquity and a specific target behavior is as follows: In the context of negative situation (i.e., pay inequity in this study) that exists among workers performing the same task, what is the degree of propinquity that influence the work motivation of the concerned worker toward the counterpart? As such, this question primarily encapsulates the main thrust of the present investigation.

A worker's awareness of a counterpart paid differently (i.e., low and high pay) performing the same job and at the 
same level has an aversive motivational consequence of double demotivation [4]. However, as reiterated earlier, this hypothesis conveys only one dimension of the individual, which is the cognitive person in explaining double demotivation. In locating the cognitive person that is embedded in the social context of work, the inclusion of ecological perception in the study of salary inequity among workers is critical. In particular, the conscious awareness and evaluation of workers of pay differential among themselves in terms of perceptual propinquity measured via physical distance may seem to have a link to double demotivation. This conjecture has never been put to an empirical test. The present study investigates two hypotheses among a sample of university students. Firstly, it is predicted that high and low paid subjects will be demotivated than those who are equitable paid. Secondly, the high and low paid subjects close in propinquity will be more demotivated than those far from their counterparts.

\section{METHOD}

\section{Participants}

The participants consist of 132 undergraduate students studying at the University of Papua New Guinea that volunteered to participate in the study. There were 84 males and 48 females with the mean age of 22.7 years $(S D=1.5)$. The years of study range from one to four, and the mean number of subjects were in their second year of study.

\section{Study Design}

The same subject design was used in the study. Each subject participated in the three conditions of high paid, low paid, and equitable paid in two work scenarios respectively.

\section{Measures}

A two page survey form presenting two imaginative different scenarios of pay differentials among workers in and between organizations were presented to the participants to imagine and respond to the questions contained in it by rating their degree of job satisfaction. In Scenario A, which presents the case of workers working in the same organization, they were asked to rate their degree of job satisfaction in scale of +3 (definitely satisfied) to -3 (definitely dissatisfied) for being either highly paid, lowly paid and equitably paid in comparison to a colleague worker doing the same job. In Scenario B, the participants were required to do the same but by comparing with another worker of the same qualification in a different organization (500 kilometers separating the two organizations) doing the same type of job. For both scenarios, the participants were asked to provide explanations for their responses respectively (see Appendix A). The pay and job satisfaction scale has been used as an effective measure of de-motivation in past studies [2, 4].

\section{Procedure}

The survey form with a consent letter was distributed to each participant at the beginning of a lecture and they were told verbally to return the completed forms as soon as possible to the lecturer of the course in the next lecture. It takes 15 to 20 minutes to complete the form. A total of 205 forms were distributed to the participants and 132 were completed and returned for analysis.

\section{RESULTS}

The data analyses were conducted using SPSS. As shown in Table 1, the job satisfaction means score of -1.86 in the same organization and mean score of -0.57 in different organization meant that the subjects' were dissatisfied with their colleague of the same qualification for being highly paid than them for performing the same job. Similarly, for low paid condition in the same organization, the participants were dissatisfied $(M=-1.99)$ but for different organization they were slightly satisfied $(M=0.95)$. However, for equitable paid condition, the participants were satisfied $(M=1.69)$ in both the same organization and different organization $(M=1.42)$.

In both scenarios, the one way analysis of variance (ANOVA) showed a significant variation between the three groups, the high and low paid groups were dissatisfied with their pay as compared to the equitable paid groups, $F(2,129)=8.4, p<.05$, thus confirming the double demotivation effect hypothesis. A post hoc analysis utilizing Scheffé procedures revealed that the high paid $(M=-1.86)$ and low paid $(M=-1.99)$ groups were significantly less satisfied than the equitable paid group $(M=1.69), p<.05$. Furthermore, there were no significant differences between the two different organizations, $F(1,130)=3.4, p>.05$. The participants were satisfied with their pay in equitable paid conditions in both scenarios.

In respect to perceptual propinquity effect on demotivation, there was significant difference between high paid group in the same organization $(M=-1.86)$ and the high paid group in different organization $(M=-0.57), F(1,130)=$ $6.04, p<.05$. Similarly, there was significant difference between low paid group $(M=-1.99)$ in the same organization and the low paid group in different organization $(M=1.09), F(1,130)=5.7, p<.05$. This means that within the same organization (Scenario A), the participants in high and low paid conditions were more dissatisfied with their

Table 1. The Means and Standard Deviations of Workers' Job Satisfaction in High, Low and Equitable Paid Conditions

\begin{tabular}{|c|c|c|}
\hline Condition Mean & Scenario A (Same Organization) & Scenario B (Different Organization) \\
\hline \hline High Paid Mean & $-1.86(S D=1.50)$ & $-0.57(S D=1.68)$ \\
\hline Low Paid Mean & $-1.99(S D=1.49)$ & $-0.95(S D=1.84)$ \\
\hline Equitable Paid Mean & $+1.69(S D=1.48)$ & $+1.42(S D=1.41)$ \\
\hline
\end{tabular}


counterparts being paid high or low for doing the same job than when perceiving the workers of the same level in another organization (Scenario B) between these two conditions. There were no significant differences between the equitable paid groups in both the same (Scenario A) and different organizations (Scenario B). The participants were satisfied with their pay in equitable paid conditions for both scenarios. The results do support the hypothesis that the closer in propinquity for workers paid differently, either high or low as compared to their counterpart of the same level, thus the demotivation effect is greater than those far in propinquity for doing the same job.

In regard to the participants' explanation for their job satisfaction rating, $41 \%$ of the subjects in the high and low aid conditions in both scenarios said that it was unfair. The other responses range from discrimination in the organization to unethical practice.

\section{DISCUSSION}

The results from the experiment confirmed both hypotheses. The high and low paid groups were dissatisfied (double demotivation) for doing the same job as their counterparts of the same job characteristics than the equitable paid groups within the same organization and likewise, when perceived from a different organization.

However, as the distance increased in terms of the subjects' perception of worker doing the same job their dissatisfaction decreased, which lend support to the perceptual propinquity hypothesis. The further a person's perception of workers inequity in salary the less psychological one is affected in a negative way.

This finding is consistent with other experimental studies of social affection [32, 33] and cross-cultural findings on proximity and relationships where individuals choose to be closer to those whom they like $[37,38]$.

However, in a review of these cross-cultural studies [37, 38], Smith and Bond [39] underscore the importance of cultural differences especially of country or ethnic origins in influencing the individual choice of liking. What these findings specifically suggest is that we tend to be closer in a positive way towards our own in-group members than out-group, which is consistent with social identity theory prediction [40].

In work context, the present study nevertheless for the first time reveal that workers who were in close propinquity at work with their working counterparts and paid differently (low/high) but doing the same job, does lead to high degree of negative psychological effect of demotivation than those far in distance. The finding add to the evolutionary notion that people tend to react intensively and adaptively to adverse event that directly concerns them and that is closer to them than ones far in distance because such threat possess a real immediate challenge to their physical and psychological survival in their environment.

The implication of the findings points simply to the issue of organization creating a favorable work environment by paying its workers on equitable basis. This suggestion has been put forward in other earlier studies on double demotivation $[1,4]$. Similarly, it is essential that workers in the same organization are treated fairly and the awards given to each employee are justified based on equity premise as espoused in the classical equity theory of Adams [11]. Furthermore, pay discrepancies have the potential to influence perceptions of organization justice, which can in turn affect work performance [41]. However, although the workers in this study do not explicitly consider pay discrepancies as a problem when comparing their pay with an employee of a different organization for doing the same task, a large number of participants do concurred that the inequity in salary is unfair.

Despite the significance of this result, one of the major shortcomings in this study is that, it did not investigate the subject's attitude behavior of liking towards the work counterpart in high, low and equitable paid conditions. It is suggested that future research should explore this area of research but by specifically focusing on employees in real work place with pay discrepancies for doing the same job. This will broaden our understanding not only of the propinquity effect but also the particular attitude behavior of workers towards each other in an organization that pay its employees differently for doing the same jobs.

Overall, such examination should illuminate the social relationships among workers in context of pay discrepancies, which is crucial for managing the work motivation of individuals in an organization. Nevertheless, the findings from this study do reveal that perceptual propinquity has an effect on double demotivation in conditions of over-and-underpayments.

\section{ACKNOWLEDGEMENTS}

The author wishes to thank Professor Stuart C. Carr of School of Psychology in Massey University for his critical comments on the earlier draft of this article and the students who participated in this project.

\section{AUTHOR IDENTIFCATION NOTES}

Direct all correspondence and reprints to Leo Marai, Psychology Strand, School of Humanities and Social Sciences, University of Papua New Guinea, P.O. Box 320, University, National Capital District, Papua New Guinea (e-mail: marail@upng.ac.pg).

\section{APPENDIX A}

\section{Instruction}

This research presents two imaginative scenarios of work and pay among colleagues in organizations. You are required to answer each question for both scenarios. There are no right or wrong answers and your responses and identity will be kept confidential. Please answer the questions as honestly as you can, according to your perception and belief about work and pay. It will take only 15 to 20 minutes of your time. 
APPENDIX A. contd....

\section{Scenario A}

1. (a). Imagine that you are working for an organization that pays your counterpart significantly higher than yourself although he or she does the same job, has the same qualification, same experience and entered the workforce about the same time as yourself. In such situation, rate your job satisfaction. (A score of -3 indicates definitely dissatisfied, -2 dissatisfied, -1 slightly dissatisfied, 0 neutral, 1 slightly satisfied, 2 satisfied, 3 definitely satisfied.

$\begin{array}{lllllll}-3 & -2 & -1 & 0 & 1 & 2 & 3\end{array}$

(b). Given the above rating of your job satisfaction, what will be your explanation?

2. (a). Imagine that you are working for an organization that pays you significantly lower than your counterpart although he or she does the same job, has the same qualification, same experience, and entered the workforce about the same time as yourself. In such situation, rate your job satisfaction. (A score of -3 indicates definitely dissatisfied, -2 dissatisfied, -1 slightly dissatisfied, 0 neutral, 1 slightly satisfied, 2 satisfied, 3 definitely satisfied).
$-3$
$\begin{array}{lll}-2 & -1 & 0\end{array}$
12
3

(b). Given the above rating of your job satisfaction, what will be your explanation?

3. (a). Imagine that you are working for an organization that pays you and your colleague the same (equal), when both of you do the same job, have the same qualification, and entered the workforce about the same time. In such situation, rate your job satisfaction. (A score of -3 indicates definitely dissatisfied, -2 dissatisfied, -1 slightly dissatisfied, 0 neutral, 1 slightly satisfied, 2 satisfied, 3definitely satisfied).

$\begin{array}{lllllll}-3 & -2 & -1 & 0 & 1 & 2 & 3\end{array}$

(b). Given the above rating of your job satisfaction, what will be your explanation?

\section{Scenario B}

1. (a). Imagine that you are working for an organization "A" and another employee works in organization "B" in a different location (organization " $\mathrm{B}$ " is 500 kilometers away from organization " $\mathrm{A}$ "). Both organizations are totally independent from one another and have different owners but same industry. Although both organizations do similar nature of the tasks and have the same structure, organization "B" pays its employee significantly higher than yourself even you both have the same qualification, do the same job, and have similar experience. In such situation, rate your job satisfaction. (A score of -3 indicates definitely dissatisfied, -2 dissatisfied, -1 slightly dissatisfied, 0 neutral, 1 slightly satisfied, 2 satisfied, 3 definitely satisfied).

$\begin{array}{lllllll}-3 & -2 & -1 & 0 & 1 & 2 & 3\end{array}$

(b). Given the above rating of your job satisfaction, what will be your explanation?

2. (a). Imagine that you are working for an organization " $A$ " and another employee works in organization " $B$ " in a different location (organization " $\mathrm{B}$ " is 500 kilometers away from organization "A"). Both organizations are totally independent from one another and have different owners but same industry. Although both organizations do similar nature of the tasks and have the same structure, organization "B" pays its employee significantly lower than yourself even you both have the same qualification, do the same job, and have similar experience. In such situation, rate your job satisfaction. (A score of -3 indicates definitely dissatisfied, -2 dissatisfied, -1 slightly dissatisfied, 0 neutral, 1 slightly satisfied, 2 satisfied, 3 definitely satisfied).

$\begin{array}{lllllll}-3 & -2 & -1 & 0 & 1 & 2 & 3\end{array}$

(b). Given the above rating of your job satisfaction, what will be your explanation?

3. (a). Imagine that you are working for organization " $A$ " and another employee works in organization "B" in a different location (organization "B" is 500 kilometers away from organization "A"). Both organizations are totally independent from one another and have different owners but same industry. These organizations do similar nature of the tasks and have the same structure, and as such, organization "B" pays its employee the same (equal) as you. This employee has the same qualification, do the same job, and have similar experience as yourself. In such situation, rate your job satisfaction. (A score of -3 indicates definitely dissatisfied, -2 dissatisfied, -1 slightly dissatisfied, 0 neutral, 1 slightly satisfied, 2 satisfied, 3 definitely satisfied).

$$
\begin{array}{lllllll}
-3 & -2 & -1 & 0 & 1 & 2 & 3
\end{array}
$$

(b). Given the above rating of your job satisfaction, what will be your explanation? 


\section{REFERENCES}

[1] Carr SC. Globalization and Culture at Work: Exploring their Combined Locality. MA: Springer 2004.

[2] Carr SC, McLoughlin D, Hodgson M, MacLachlan M. Effects of unreasonable pay discrepancies for under and overpayment on double de-motivation. Genet Soc Gen Psychol Monogr 1996; 122: 475-94.

[3] MacLachlan M, Carr SC. Demotivating the doctors: the double demotivation hypothesis in Third World health services. J Med Manag 1993; 7: 6-10.

[4] Marai L. Double de-motivation and negative social affect among teachers in Indonesia. South Pacific J Psychol 2002/3; 14: 1-7.

[5] Carr SC, MacLachlan M. The social psychology of development work: The double de-motivation hypothesis. Malawi J Soc Sci 1993/1994; 16: 1-8.

[6] MacLoughlin D, Carr SC. Equity sensitivity and double demotivation. J Social Psychol 1997; 137: 668-70.

[7] Carr SC, Inkson K, Thorn K. From brain drain to talent flow: a motivational theory of global careers. J World Bus 2005; 40: 38698

[8] Marai L. Double de-motivation and intrinsic motivation among teachers in Indonesia. J Psikol 2001; 28: 61-75.

[9] Taris TW, Horn JE, Schaufeli WB, Schreurs PJG. Inequity, burnout and psychological withdrawal among teachers: a dynamic exchange. Anxiety Stress Coping 2004; 17: 103-22.

[10] Carr SC, MacLachlan M, Campbell D. Development through education collaboration: facilitating social equity. Higher Educ Policy 1997; 10: 81-91.

[11] Adams JS. The equity in social exchange. Adv Exp Soc Psychol 1965; 2: 267-99.

[12] Carr SC, Hodgson MR, Vent DH, Purcell IP. Pay diversity across work teams: Double de-motivating influences? J Manag Psychol 2005; 20: 417-39.

[13] Gibson JJ. The Senses Considered as Perceptual Systems. Boston: Houghton 1996.

[14] Gibson JJ. The Ecological Approach to Visual Perception. Boston: Houghton 1979.

[15] Baron RM. Contrasting approaches to social knowing: an ecological perspective. Pers Soc Psychol Bull 1980; 6: 590-600.

[16] Baron RM. In: Harvey JH, Ed. Social knowing from an ecologicaleven perspective: a consideration of the relative dominos of power for cognitive and perceptual modes of knowing. Cognition, social behavior and the environment. Hillsdale NJ: Erlbaum 1980; pp. 6192.

[17] Baron RM. Distinguishing between perceptual and cognitive "groundings" for consistency theories: epistemological implications. Pers Soc Psychol Bull 1984; 10: 165-74.

[18] Kassin SM, Baron RM. In: Harvey J, Weary EG, Eds. Basic Determinants of Attribution and Social Perception. Attribution:
Basic issues and applications New York: Academic Press 1985; pp. 37-64.

[19] Kassin SM, Baron RM. On the basicity of social perception cues: developmental evidence for adult processes? Soc Cognit 1986; 4: 180-200

[20] Lowe CA, Kassin SM. A perceptual view of attribution: theoretical and methodological implications. Pers Soc Psychol 1980; 6: 53242.

[21] McArthur LZ. Illusory causation and illusory correlation: two epistemological accounts. Pers Soc Psychol Bull 1980; 6: 507-19.

[22] McArthur LZ, Baron R. Toward an ecological theory of social perception. Psychol Rev 1983; 90: 215-38.

[23] Neisser U. Cognition and Reality. San Francisco: Freeman 1976.

[24] Neisser U. On "Social Knowing". Pers Soc Psychol 1980; 1: 35-59.

[25] Weary G, Swanson H, Harvey JH, Yarkin KL. A molar approach to social knowing. Pers Soc Psychol Bull 1980; 6: 574-81.

[26] Zebrowitz-McArthur L. In: Bond MH, Ed. Person perception in cross-cultural perspective: the cross-cultural challenge to social psychology. Beverley Hills CA: Sage 1988; pp. 245-65

[27] Fiske ST, Taylor SE. Social Cognition. $2^{\text {nd }}$ ed. New York: McGraw-Hill Inc 1991.

[28] Zebrowitz LA. Social Perception. Pacific Grove CA: Brooks-Cole 1990

[29] Baum A, Valins S. Architecture and Social behavior: Psychological Studies of Social Density. Hillsdale, UJ: Erlbaum 1977.

[30] Baum A, Aiello JR, Calesnick LE. Crowding and personal control: Social density and the development of learned helplessness. J Pers Soc Psychol 1978; 36: 1000-1011.

[31] Baum A, Davis GE. Reducing the stress of high-density living: An architectural intervention. J Pers Soc Psychol 1980; 38: 471-81.

[32] Patterson ML, Sechrest LB. Interpersonal distance and impression formation. J Pers 1970; 38: 161-66.

[33] Allgeier ER, Byrne D. Attraction toward the opposite sex as a determinant of physical proximity. J Soc Psychol 1973; 90: 213-19.

[34] Milgram S. Some conditions of obedience and disobedience to authority. Hum Relat 1965; 18: 57-75.

[35] Milgram S. Obedience to Authority: an Experimental View. New York: Harper \& Row 1974

[36] Seta J, Paulus P, Shkade, J. Effects of group size and proximity under cooperative and competitive conditions. J Pers Soc Psychol 1976; 34: 47-53

[37] Watson OM, Graves TD. Qualitative research in proxemic behavior. Am Anthropol 1966; 68: 971-85.

[38] Watson OM. Proxemic Behavior: A Cross-Cultural Study. The Hague: Mouton 1970.

[39] Smith PB, Bond MH. SocialPpsychology Across Cultures: Analysis and Perspective. Cambridge Hevester Wheatsheaf 1993.

[40] Tajfel H, Ed. Differentiation between Social Groups: Studies in Intergroup Behavior. London: Academic Press 1978.

[41] Colquitt JA, Conlon DE, Wesson MJ, Porter COLH, Yee NK. Justice at the millennium: a meta-analytic review of 25 years of organization justice research. J Appl Psychol 2001; 86: 425-45.

(C) Leo Marai; Licensee Bentham Open.

This is an open access article licensed under the terms of the Creative Commons Attribution Non-Commercial License (http://creativecommons.org/licenses/by-nc/3.0/) which permits unrestricted, non-commercial use, distribution and reproduction in any medium, provided the work is properly cited. 